\title{
IL-6 Is Constitutively Expressed During Lung Morphogenesis and Enhances Fetal Lung Explant Branching
}

\author{
CRISTINA NOGUEIRA-SILVA, MARTA SANTOS, MARIA J. BAPTISTA, RUTE S. MOURA, AND JORGE CORREIA-PINTO \\ Fetal and Neonatal Physiology [C.N.-S., M.S., M.J.B., R.S.M., J.C.-P.], Life and Health Sciences Research Institute (ICVS), \\ University of Minho, 4709-057 Braga, Portugal; Divisions of Pediatric Cardiology [M.J.B.] and Surgery [J.C.-P.], Hospital S João, \\ 4202-451 Porto, Portugal
}

\begin{abstract}
Previous studies have shown that chorioamnionitis, with increased IL-6, promotes fetal lung maturation and decreases the incidence of respiratory distress syndrome in premature neonates. However, the expression pattern and the effects of IL-6 on fetal lung growth mechanisms remain unknown. IL-6 expression was assessed by in situ hybridization and by real-time PCR between 14.5 and $21.5 \mathrm{~d}$ postconception. Normal and nitrofen-induced hypoplastic lung explants were cultured with increasing IL-6 doses or IL-6 neutralizing antibodies. Branching, cellular proliferation (Ki-67) and MAPK phosphorylation in fetal lung explants were analyzed. Pulmonary primitive epithelium expressed IL-6 constitutively throughout all gestational ages, displaying highest levels during earliest stages. In normal and hypoplastic lung explants, IL-6 neutralizing antibodies significantly reduced, whereas IL-6 supplementation induced a biphasic effect (lower doses increased, while the highest dose did not accomplish additional effect) on branching and cellular proliferation. IL-6 enhanced p38-MAPK phosphorylation without changing MEK1/2 and JNK pathways. The present study suggests a physiological role for IL-6 on pulmonary branching mechanisms most likely involving p38-MAPK intracellular signalling pathway. (Pediatr Res 60: 530-536, 2006)
\end{abstract}

D uring the last decades, the regulating mechanisms of lung branching have been unraveled. This morphogenic process occurs through fundamental cross-talk interactions between epithelial and mesenchymal tissues via extremely complex processes, involving a multitude of effectors including growth factors, extracellular matrix interactions, and hormones (1). The understanding of these mechanisms has clinical relevance since it can open new perspectives in the treatment of fetal lung hypoplasia as well as modulation of lung repair.

IL-6 is a pleiotropic cytokine with important roles on acute inflammatory response, infection, hematopoiesis, regulation of bone absorption, cell growth, differentiation, survival, apoptosis, and proliferation (2-4). Several studies have emphasized the importance of IL-6 signaling in several processes of

Received January 26, 2006; accepted June 17, 2006.

Correspondence: Jorge Correia-Pinto, M.D., Ph.D., Escola de Ciências da Saúde, Universidade do Minho. Campus de Gualtar: CPII (piso 3). 4709-057 Braga, Portugal; e-mail: jcp@ecsaude.uminho.pt

This project was funded by Fundação para a Ciência e a Tecnologia (POCI/SAUOBS/56428/2004). MS was supported by Fundação para a Ciência e a Tecnologia (reference SFRH/BD/9631/2002) through the G.A.B.B.A. Programme, University of Porto, Portugal. RSM was supported by Fundação para a Ciência e a Tecnologia (reference SFRH/BPD/15408/2005).

DOI: 10.1203/01.pdr.0000242300.09427.3b branching organs such as embryonic submandibular gland development $(5,6)$, mammary gland remodeling (7), benign and malign prostate growth $(8,9)$, and lung maturation (10).

In fact, several clinical and animal-based studies suggest that antenatal exposure to inflammatory mediators may improve lung volume and compliance as well as accelerate fetal lung maturation (10). In humans, it was demonstrated that IL-6 elevation in fetuses with chorioamnionitis promoted fetal lung maturation by enhancing surfactant protein A (SP-A) synthesis. In fact, fetal IL-6 is a regulatory cytokine of pulmonary surfactant proteins and plays an important role in lung maturity decreasing the incidence of respiratory distress syndrome in preterm neonates (11). In different animal models such as the rat (12), the rabbit (10), and the sheep (13), it was shown that intra-amniotic injection of endotoxin or continuous administration of IL-6 improved lung function by increasing expression of surfactant apoprotein mRNA $(12,14,15)$.

Recently, it was demonstrated that IL-6 plays an important modulatory role in lung angiogenesis (16), a fundamental process in fetal lung morphogenesis (17). Moreover, Dame and Juul (4) demonstrated that IL-6 receptor was widely distributed in developing human fetuses, including in bronchial epithelial cells. Such findings suggest an IL-6 nonhematopoietic role in the developing fetus.

IL-6 exerts its action via the signal transducer gp130 leading to the activation of the JAK/STAT (Janus kinase/signal transducer and activator of transcription) and MAPK cascades (2). Many of the effectors that modulate fetal lung branching morphogenesis seem to activate signaling pathways that converge into the mitogen-activated protein MAPK (18). There are three major families of MAPK: the extracellular signalregulated kinases-1 and -2 (ERK1/2), c-Jun $\mathrm{NH}_{2}$-terminal kinases (JNK), and p38 kinase.

Although several reports demonstrated that IL- 6 can modulate lung development, the IL-6 expression pattern as well as its effects during early lung development are largely unknown. Therefore, in the current study, IL-6 expression during antenatal lung development was characterized. Furthermore, the effects of IL-6 supplementation or IL-6 neutralizing antibodies in normal and hypoplastic fetal lung explants were evaluated.

Abbreviations: $\mathbf{D}_{\mathbf{0}}$, day 0; $\mathbf{D}_{\mathbf{4}}$, day 4; dpc, days postconception; ISH, in situ hybridization; MAPK, mitogen-activated protein kinase 
Additionally, the potential activation of MAPK pathway by IL-6 was investigated.

\section{MATERIALS AND METHODS}

Animal experiments were performed according to the Portuguese law for animal welfare. Animals were housed in an accredited mouse house and treated as specified by the recommendations of the Guide for the Care and Use of Laboratory Animals published by the US National Institutes of Health (National Institutes of Health Publication No.85-23, revised 1996).

Animal model and experimental design. Sprague-Dawley female rats (225g; Charles-River, Barcelona, Spain) were maintained in appropriate cages under controlled conditions and fed with commercial solid food. The rats were mated and checked daily for vaginal plug. The day of plugging was defined as gestational $\mathrm{d} 0.5$ for time dating purposes. Nine and a half dpc pregnant rats were exposed to $100 \mathrm{mg}$ of nitrofen (2,4-dichlorophenyl-p-nitrophenylether) dissolved in $1 \mathrm{~mL}$ of olive oil administered by gavage (nitrofen-induced hypoplastic lungs: nitrofen group) or with an equal volume of vehicle (normal lungs: normal group) (19). For in situ hybridization and PCR studies, normal lungs were used, whereas for fetal lung explant cultures normal and nitrofeninduced hypoplastic lungs were used.

From the normal group, fetuses were removed by cesarean section at 14.5, $15.5,17.5,19.5$, and $21.5 \mathrm{dpc}$. Fetuses at $14.5 \mathrm{dpc}$ were processed in toto for whole mount hybridization studies. Fetuses older than $14.5 \mathrm{dpc}$ were killed by decapitation and lungs were excised, processed, and embedded in paraffin for in situ hybridization. Random left lung samples were collected for the quantification of IL-6 expression by real-time PCR. These samples were immersed in RNAlater (QIAGEN GmbH, Hilden, Germany) and stored at $-80^{\circ} \mathrm{C}$.

Fetuses harvested at $13.5 \mathrm{dpc}$ from normal and nitrofen groups were dissected and lungs collected for explant culture. After $4 \mathrm{~d}$ culture, explants from each group were collected either for immunohistochemistry or Western blot analysis.

ISH studies. Digoxigenin-labeled IL-6 probe was synthesized from a 901 bp fragment of the coding sequence of IL-6, inserted on a pBluescript KSvector (kindly supplied by Dr. Georg H. Fey, University of Erlangen, Nurnberg, Germany). The plasmid was linearized with BamHI and T3 RNA polymerase was used to synthesize the antisense riboprobe. The in vitro transcription reaction was performed using DIG RNA Labeling Mix (Roche Molecular Biochemicals, Mannheim, Germany), according to the manufacturer's instructions.

Whole mount. Embryos were fixed overnight at $4{ }^{\circ} \mathrm{C}$ in $4 \%$ paraformaldehyde (PFA), rinsed in $1 \times$ PBS, dehydrated through a methanol series, and stored in $100 \%$ methanol at $-20^{\circ} \mathrm{C}$. Whole mount ISH was performed as previously described (20). Embryos were visualized as whole mounts in PBT (PBS, 0.1\% Tween20) under binocular microscopy (Leica MZFLIII; Leica Geosystems AG, Heerbrugg, Switzerland), and photographed using Sony 3CCD Color Video Camera.

Paraffin sections. Tissue sections (10 $\mu \mathrm{m}$ thick) were processed for ISH as previously described by Strahle et al. (21). ISH slides were observed and photographed on light microscope with an Axiocam color video camera (Carl Zeiss GmbH, Jena, Germany).

RNA extraction and reverse transcription. Total mRNA from left lung samples of 30 fetuses ( $15.5 \mathrm{dpc}, n=9 ; 17.5 \mathrm{dpc}, n=7 ; 19.5 \mathrm{dpc}, n=7 ; 21.5$ dpc, $n=7$ ) was extracted using the RNeasy Mini Kit Protect (QIAGEN $\mathrm{GmbH}$ ). Total mRNA quantification was done by spectrophotometry (BioPhotometer, Eppendorf AG, Hamburg, Germany).

Reverse transcription was performed as previously described by Santos $e t$ al. (22).

Quantitative real-time PCR. Quantitative real-timePCR was performed as previously described by Santos et al. (22).

Primer design was based on available sequences in GenBank (NCBINLM-PubMed-Gene). All the primers are intron-spanning (Table 1). For IL-6 and $\beta$-actin primer sets, standard amplification curves (ST curves) were made with randomly selected cDNA samples setting $r=0.99$. In all the samples IL-6 expression was normalized for $\beta$-actin.

Fetal lung explant cultures. Harvesting and dissection of $13.5 \mathrm{dpc}$ lungs was made in DPBS (Cambrex, East Rutherford, NJ) under a dissection microscope (Leica MZFLIII). The lungs were transferred to Nucleopore membranes with an $8 \mu \mathrm{m}$ pore size (Whatman, Clifton, NJ) and incubated in a 12-well culture plates from Costar (Corning, NY). The membranes were presoaked in DMEM (Cambrex) for $1 \mathrm{~h}$ before the explants were placed on them. Floating cultures of the explants were incubated in $200 \mu \mathrm{L}$ of $50 \%$ DMEM, 50\% nutrient mixture F-12 (Invitrogen, Carlsbad, CA) supplemented with $100 \mu \mathrm{g} / \mathrm{mL}$ streptomycin, $100 \mathrm{units} / \mathrm{mL}$ penicillin (Invitrogen), 0.25 $\mathrm{mg} / \mathrm{mL}$ ascorbic acid (Sigma Chemical, Poole, Dorset, UK) and 10\% FCS (Invitrogen). The fetal lung explants were incubated in a $5 \% \mathrm{CO}_{2}$ incubator at $37^{\circ} \mathrm{C}$ for $96 \mathrm{~h}$, and the medium was replaced every $48 \mathrm{~h}$. The branching morphogenesis was monitored daily by photographing the explants. At $\mathrm{d} 0$ $\left(\mathrm{D}_{0}: 0 \mathrm{~h}\right)$ and $\mathrm{d} 4\left(\mathrm{D}_{4}: 96 \mathrm{~h}\right)$ of culture, the total number of peripheral airway buds (branching) in all lung explants was determined, whereas the epithelial perimeter was measured using AxionVision Rel. 4.3 (Carl Zeiss GmbH). The results of branching and epithelial perimeter were expressed as $\mathrm{D}_{4} / \mathrm{D}_{0}$ ratio.

IL-6 supplementation studies. Twelve normal and 12 nitrofen-hypoplastic lung explants were used as control $(0 \mathrm{pg} / \mathrm{mL})$. Additionally, recombinant rat IL-6 (R \& D Systems, Minneapolis, MN) was added daily to normal and nitrofen-induced hypoplastic lung explants to achieve a final concentration of $0.01,0.1,1,10,100 \mathrm{pg} / \mathrm{mL}$ (normal lungs: $0.01, n=8 ; 0.1, n=8 ; 1, n=8$; $10, n=10 ; 100, n=8$. Hypoplastic lungs: $0.01, n=10 ; 0.1, n=9 ; 1, n=$ 9; $10, n=12 ; 100, n=8$ ).

IL-6 neutralizing studies. Normal explants were treated daily with $\mathrm{IgG}$ anti-rat IL-6 neutralizing antibody $(n=12)$ at concentration of $1.0 \mu \mathrm{g} / \mathrm{mL}(30$ times the concentration previously shown to suppress IL-6 effect) (R \& D Systems). Nonspecific effects were evaluated by adding identical concentration of normal goat IgG control antibody $(n=10)$ (R \& D Systems).

Proliferation assay by immunohistochemistry. Nontreated $(0 \mathrm{pg} / \mathrm{mL})$ and IL-6 treated (10 and $100 \mathrm{pg} / \mathrm{mL})$ normal and nitrofen explants as well as normal explants treated with normal goat IgG and IgG anti-rat IL-6 neutralizing antibodies (interruption studies) were processed for proliferation assay (5 per each group). Ki-67 immunostainings were performed on formalin-fixed and paraffin-embedded lung explants. Sections $(5 \mu \mathrm{m})$ were placed on SuperFrost Plus slides (Menzel-Glaser, Braunschweig, Germany). The primary antibody, a monoclonal rabbit serum anti-Ki-67 (NeoMarkers, Fremont, CA), was used in a 1:200 dilution. After dewaxing in xylene and rehydration in ethanol, the samples were incubated in 3\% hydrogen peroxide in methanol to quench endogenous peroxidase. Antigen retrieval was achieved by boiling in $10 \mathrm{mM}$ citrate buffer followed by cool down at room temperature. Samples were blocked with 5\% BSA (Roche Molecular Biochemicals). Incubation of the primary antibody occurred at $4^{\circ} \mathrm{C}$ overnight. Negative control reactions included omission of the primary antibody. Incubation with the UltraVision detection system anti-polyvalent horseradish peroxidase (Lab Vision Corporation, Fremont, CA) was carried accordingly to manufacturer's instructions. To visualize the peroxidase activities in sections, diaminobenzidine tetrahydrochloride was used. Sections were counterstained with hematoxylin.

For cell proliferation quantification, epithelial and mesenchymal Ki-67 positive and negative cells were counted at $\times 20$ magnification (Olympus DP 70, Cell P; Olympus, Hamburg, Germany) in four independent peripheral areas per explant. Results are presented as percentage of the ratio of positiveto-total cells normalized for lung section area.

Western blot analysis. Nontreated $(0 \mathrm{pg} / \mathrm{mL})$ and $10 \mathrm{pg} / \mathrm{mL}$ IL- 6 treated normal explants were processed for Western blot analysis. Proteins from lung explants were obtained according to Kling et al. (18). Five micrograms of protein were loaded onto $12.5 \%$ acrylamide minigels, electrophoresed at 100 $\mathrm{V}$ at room temperature, and then transferred to Hybond-C Extra (Amersham Pharmacia Biotech, Inc., Piscataway, NJ). Blots were probed with p38, p44/42 (ERK1/2), JNK, phospho-p38 (dp-p38), phospho-p44/42 (dp-ERK1/ 2), phospho-JNK (dp-JNK) MAb (New England Biolabs, US) according to manufacturer's instructions. For loading control, blots were probed with $\beta$-tubulin MAb (Santa Cruz Biotechnology Inc., US). Afterward blots were incubated with a secondary horseradish peroxidase conjugate (New England

Table 1. Primers used for quantitative PCR

\begin{tabular}{cclc}
\hline Gene & Accession number & \multicolumn{1}{c}{ Primer set } & Product size (bp) \\
\hline IL-6 & NM_012589 & 5'-CAA GAG ACT TCC AGC CAG-3' & 141 \\
& & 5'-CTC CGA CTT GTG AAG TGG T-3' & \\
& NM_031144 & 5'-GAT TTG GCA CCA CAC TTT CTA CA-3' & 114 \\
& & 5'-ATC TGG GTC ATC TTT TCA CGG TTG G-3' & \\
\hline
\end{tabular}




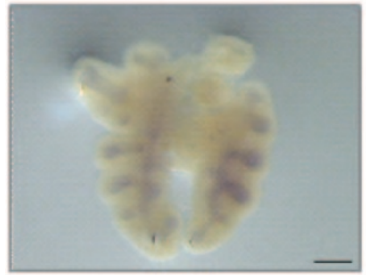

14.5 dpe

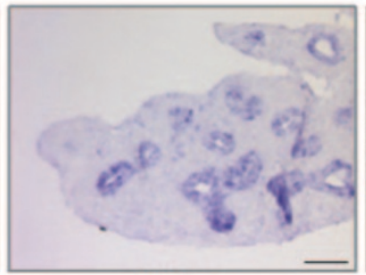

15.5 dpe

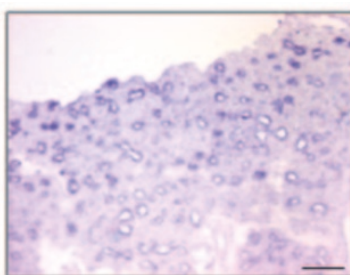

17.5 dpe

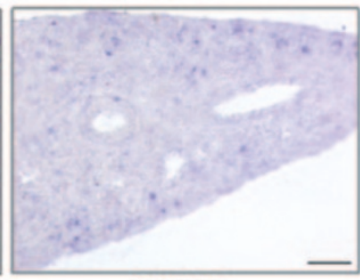

19.5 dpe

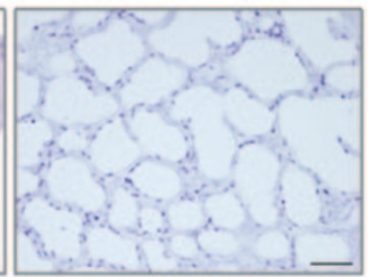

21.5 dpe

Figure 1. IL-6 expression pattern during normal rat lung development. ISH studies showed that in normal fetal lung, IL-6 expression was localized to the primitive airway epithelium. The positive IL-6 signal was detected during all the studied developmental ages, predominantly during the pseudoglandular phase (14.5 and $15.5 \mathrm{dpc}$ ). Scale bar: $14.5 \mathrm{dpc}=4960 \mu \mathrm{m} ; 15.5,17.5,19.5$, and $21.5 \mathrm{dpc}=100 \mu \mathrm{m}$.

Biolabs, Beverly, MA), developed with Super Signal West Femto Substrate (Pierce Biotechnology, Inc., Rockford, IL) and exposed to Hyperfilm ECL (Amersham Pharmacia Biotech, Inc.).

Statistical analysis. All quantitative data are presented as mean \pm SEM. Statistical analysis was performed by one-way ANOVA (real-time PCR and morphometric explants studies) or three-way ANOVA (proliferation studies) on ranks and the Student-Newman-Keuls test was used for post-test analysis. For IL-6 neutralizing studies (morphometric and proliferation studies), $t$ test analysis was used. Statistical significance was set at $p<0.05$.

\section{RESULTS}

IL-6 expression pattern during normal pulmonary development. ISH studies revealed that IL-6 was expressed throughout all studied gestational ages in fetal lung (Fig. 1). Figure 1 illustrates IL-6 mRNA predominantly expressed in primitive lung epithelium presenting significant expression since the earliest studied stage of rat lung development (14.5 dpc). IL-6 mRNA levels appeared highest during pseudoglandular stage (14.5 and $15.5 \mathrm{dpc}$ ) decreasing during subsequent stages of lung development.

Real-time PCR analysis. The ISH results of IL-6 expression prompted us to perform real-time PCR to quantify relative expression of IL-6 levels during normal lung development (Fig. 2). The mRNA levels of $\beta$-actin were not significantly altered during gestation and were subsequently used to normalize the expression data for IL-6. In Figure 2, mRNA levels

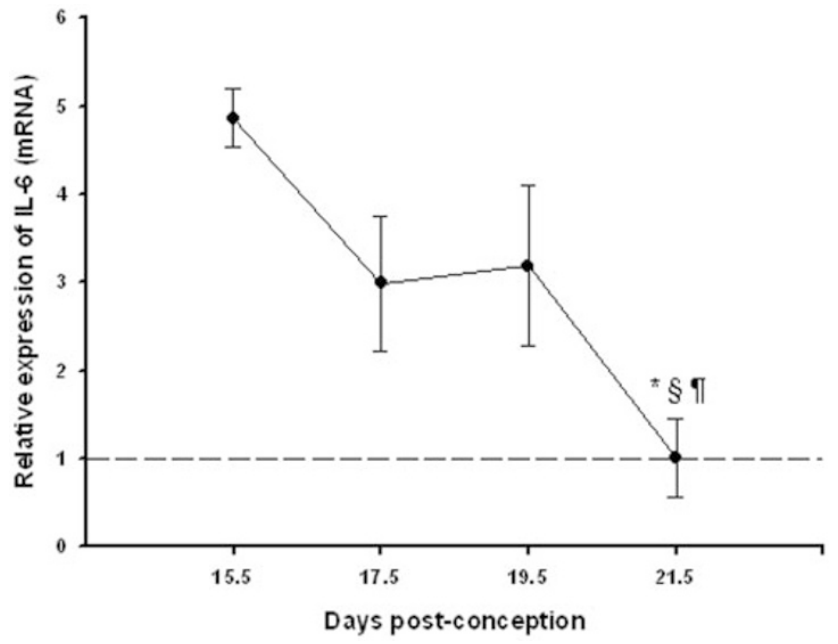

Figure 2. IL-6 mRNA levels during normal fetal rat lung development, expressed in arbitrary units normalized for $\beta$-actin ( $15.5 \mathrm{dpc}: n=9 ; 17.5 \mathrm{dpc}$ : $n=7 ; 19.5$ dpc: $n=7 ; 15.5 \mathrm{dpc}: n=7)$. *p $<0.05$ vs $15.5 \mathrm{dpc}, \S p<0.05$ vs $17.5 \mathrm{dpc}$, II $p<0.05$ vs $19.5 \mathrm{dpc}$. of IL-6 normalized to $\beta$-actin are presented. In normal fetal lung development, IL-6 was expressed in all studied gestational ages. IL-6 mRNA levels were significantly higher in the earliest assessed gestational age $(15.5 \mathrm{dpc})$, which corresponds to the pseudoglandular stage of lung development. In the subsequent stages of lung development, as suggested by ISH results, IL-6 mRNA levels decreased.

IL-6 supplementation studies. To evaluate IL-6 role during lung morphogenesis, normal and hypoplastic fetal lung explants were treated with different doses of recombinant rat IL-6. In Figure 3, representative examples of normal (Fig. 3A) and hypoplastic (Fig. 3B) fetal lung explants treated with increasing IL- 6 doses are illustrated. IL- 6 appears to have an enhancing effect on lung explants growth, except with the highest dose.

The results of morphometric analysis on fetal lung explants are summarized in Figure 4. In normal and nitrofen explants, increasing IL-6 doses induced a biphasic effect on total number of peripheral airway buds as well as on epithelial perimeter. Lower IL-6 doses enhanced explant growth, whereas the highest dose did not induce significant effect. In normal explants (Fig. 4, $A$ and $C$ ), IL-6 treatment induced maximal growth rates at $10 \mathrm{pg} / \mathrm{mL}$, whereas in nitrofen explants, the total number of peripheral airway buds (Fig. $4 B$ ) was maximal at $10 \mathrm{pg} / \mathrm{mL}$ and epithelial perimeter (Fig. $4 D$ ) at $1 \mathrm{pg} / \mathrm{mL}$. The number of peripheral airway buds and the epithelial
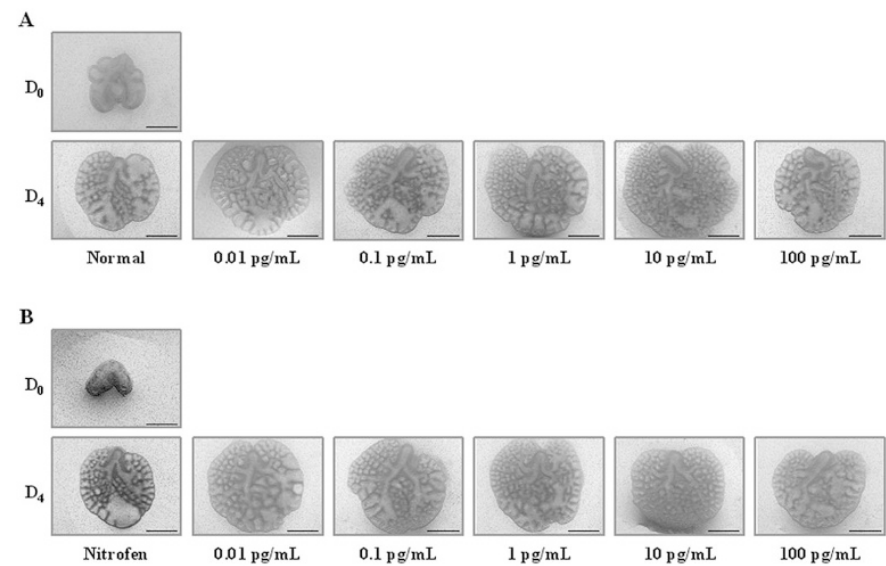

Figure 3. Branching morphogenesis in rat lung explant system. (A) Normal lung explants. $(B)$ Nitrofen-hypoplastic lung explants. Upper panel is representative of lungs at $13.5 \mathrm{dpc}$ at culture d $0\left(\mathrm{D}_{0}\right)$. Bottom panel represents lungs, treated with different IL- 6 doses, at d $4\left(D_{4}\right)$. Scale bar $=6349 \mu \mathrm{m}$ (all images at same magnification). 

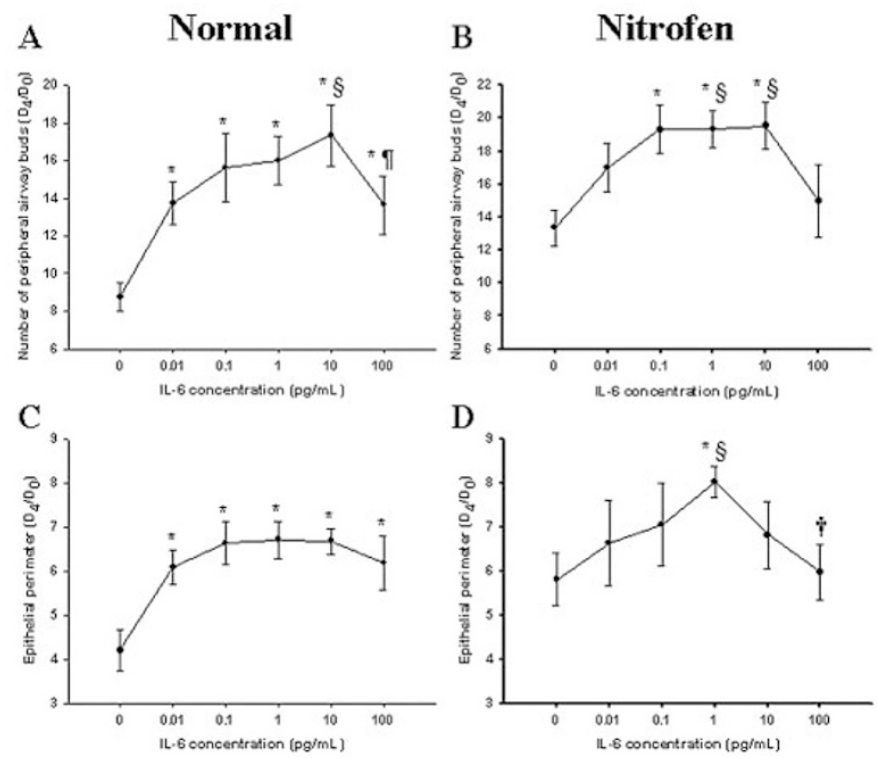

Figure 4. Morphometric analysis of lung explant cultures treated with different IL-6 doses. (A) Number of total airway buds in normal explants. (B) Number of total airway buds in hypoplastic explants. $(C)$ Epithelial perimeter in normal explants. $(D)$ Epithelial perimeter in hypoplastic explants. Results are expressed as $\mathrm{D}_{4} / \mathrm{D}_{0}$ ratio (Normal lungs: $0, n=12 ; 0.01, n=8 ; 0.1, n=$ $8 ; 1, n=8 ; 10, n=10 ; 100, n=8$. Hypoplastic lungs: $0, n=12 ; 0.01, n$ $=10 ; 0.1, n=9 ; 1, n=9 ; 10, n=12 ; 100, n=8) . * p<0.05$ vs IL-6 at $0 \mathrm{pg} / \mathrm{mL}, \S p<0.05 v s$ IL-6 at $0.01 \mathrm{pg} / \mathrm{mL}, \dagger p<0.05$ vs IL-6 at $1 \mathrm{pg} / \mathrm{mL}$, If $p<0.05$ vs IL-6 at $10 \mathrm{pg} / \mathrm{mL}$.

perimeter were significantly reduced in nitrofen when compared with normal explants at $\mathrm{D}_{0}$ (Table 2). However, in the absence of IL- 6 treatment and after $4 \mathrm{~d}$ in culture no significant differences between normal and nitrofen groups were observed. After IL- 6 treatment, $\mathrm{D}_{4} / \mathrm{D}_{0}$ ratio of the number of peripheral airway buds (Fig. $4 B$ ) and epithelial perimeter (Fig. $4 D$ ) was always higher in the nitrofen group than in the normal group, independently of IL-6 dose.

Figure 5 shows cellular proliferation assay in normal and nitrofen explants nontreated and treated with either $10 \mathrm{pg} / \mathrm{mL}$ (dose of maximal effect) or $100 \mathrm{pg} / \mathrm{mL}$ (dose with lesser effect). Treatment with $10 \mathrm{pg} / \mathrm{mL}$ of IL-6 induced a significant increase on proliferation rate in normal and nitrofen explants, whereas in explants treated with $100 \mathrm{pg} / \mathrm{mL}$ of IL-6 a significant decrease is evident in such proliferation when compared with $10 \mathrm{pg} / \mathrm{mL}$. No significant differences between normal and nitrofen groups were observed, although there is a statistically significant interaction between variables: groups $\times$ IL- 6 doses

Table 2. Number of peripheral airway buds and epithelial perimeter in normal and nitrofen groups, at $d 0$ and 4 of culture

\begin{tabular}{lccccc}
\hline & \multicolumn{2}{c}{$\begin{array}{c}\text { Number of } \\
\text { peripheral airway buds }\end{array}$} & & \multicolumn{2}{c}{ Epithelial perimeter } \\
\cline { 2 - 3 } \cline { 5 - 6 } Group & $\mathrm{D}_{0}$ & $\mathrm{D}_{4}$ & & $\mathrm{D}_{0}$ & $\mathrm{D}_{4}$ \\
\hline Normal & $6 \pm 0$ & $54.8 \pm 4.9$ & & $7054 \pm 255$ & $31512 \pm 3887$ \\
Nitrofen & $4.33 \pm 0.42$ & $51.8 \pm 4.76$ & & $5046 \pm 294$ & $29222 \pm 3522$ \\
$p$ Value & $<0.01$ & $\mathrm{NS}$ & & $<0.01$ & $\mathrm{NS}$ \\
\hline
\end{tabular}

NS, not statistically significant.
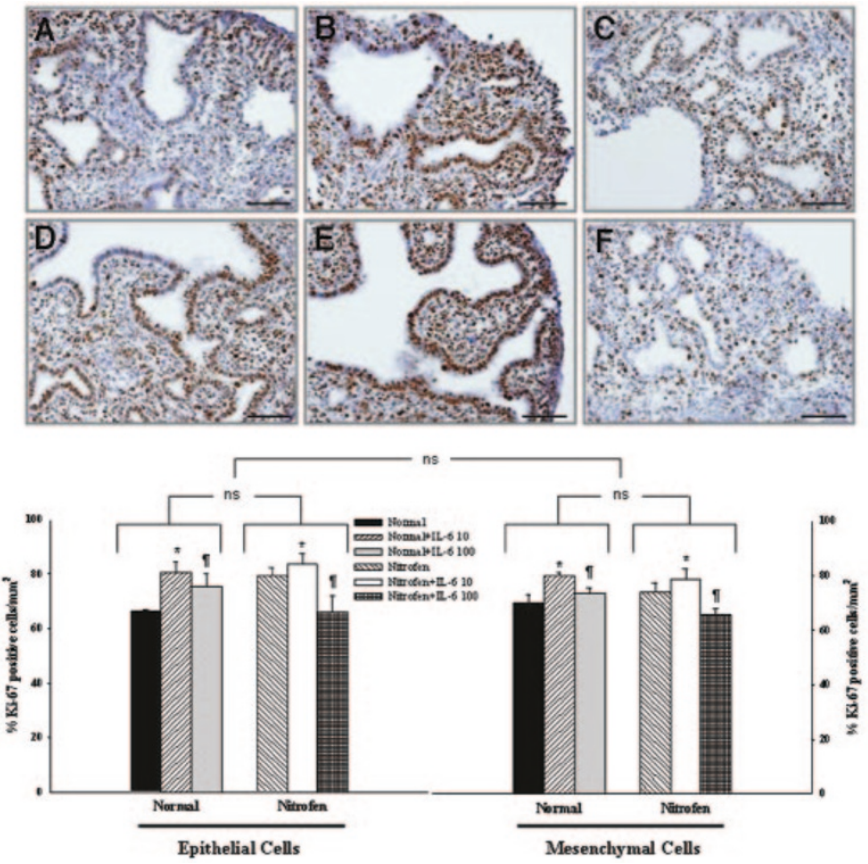

Figure 5. Cellular proliferation assay in normal and nitrofen explants by Ki-67 immunohistochemistry. (A) Nontreated normal explants. (B) $10 \mathrm{pg} / \mathrm{mL}$ IL-6 treated normal explants. (C) $100 \mathrm{pg} / \mathrm{mL}$ IL-6 treated normal explants. $(D)$ Nontreated hypoplastic explants. $(E) 10 \mathrm{pg} / \mathrm{mL}$ IL-6 treated hypoplastic explants. $(F) 100 \mathrm{pg} / \mathrm{mL}$ IL-6 treated hypoplastic explants (five lungs analyzed per each group). The bottom graphics presents epithelial and mesenchymal cellular proliferation quantification. Results are expressed as percentage of positive-to-total cells ratio normalized for $\mathrm{mm}^{2}$. Scale bar $=100 \mu \mathrm{m}$ (all images at same magnification). ${ }^{*} p<0.05 v s$ normal or nitrofen explants nontreated, If $p<0.05 v s$ IL-6 at $10 \mathrm{pg} / \mathrm{mL}$. ns, not statistically significant.
A

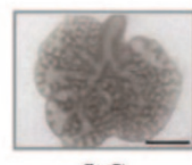

IgG
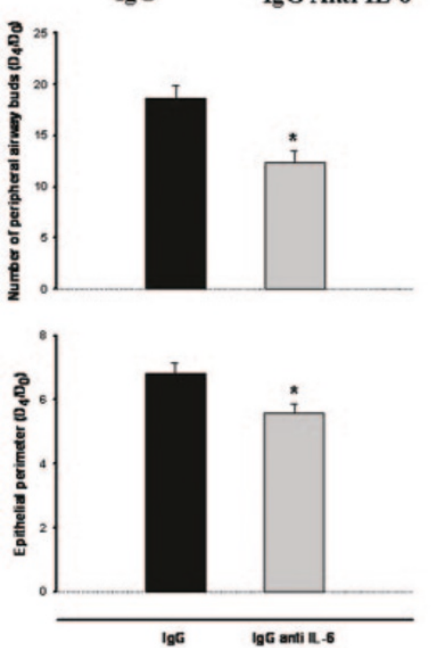

B

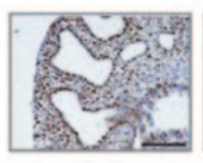

IgG
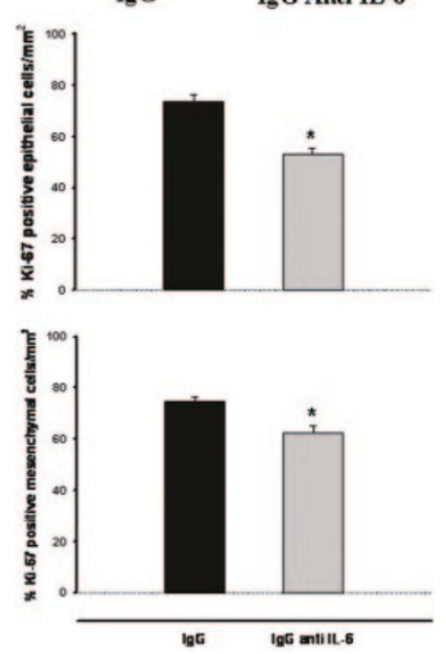

Figure 6. IL-6 neutralizing studies in normal lung explants treated with normal goat $\operatorname{IgG}$ (control $n=10)$ and IgG anti-rat IL-6 antibodies $(n=12)$. A: Branching morphogenesis (upper panel) and morphometric analysis of lung growth (middle and bottom panels). B: Cellular proliferation assay (5 lungs analyzed per each group). Scale bar $\mathrm{A}=6349 \mu \mathrm{m}, \mathrm{B}=100 \mu \mathrm{m} . p<$ $0.01: * v s$. goat IgG. 


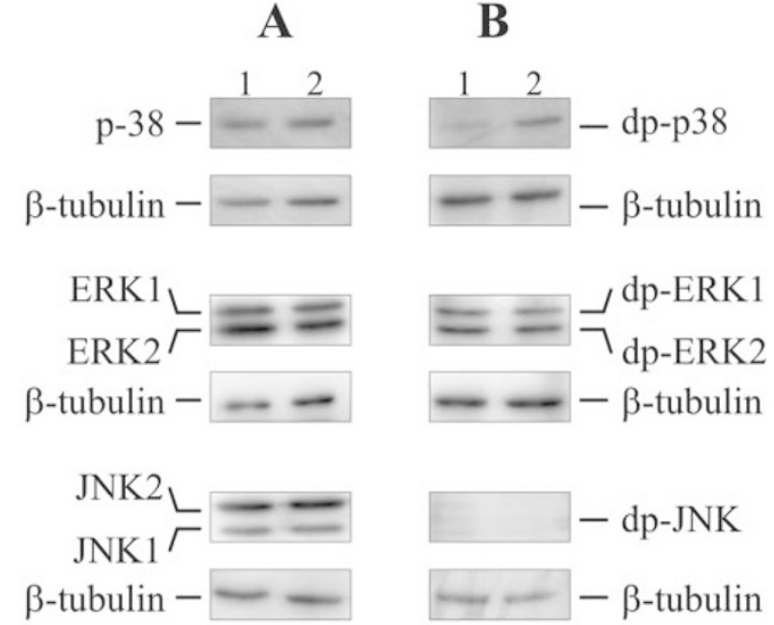

Figure 7. MAPK activities in nontreated (1) and treated with IL-6 at 10 $\mathrm{pg} / \mathrm{mL}$ (2) lung explants. Western blot analysis of MAPK with MAbs to p38, ERK1/2 and JNK1/2 (A) and to diphosphorylated forms of p38 (dp-p38), ERK1/2 (dp-ERK1/2) and SAPK/JNK (dp-JNK1/2) (B). Control loading was performed using $\beta$-tubulin (55 KDa). ERK1 and 2 correspond to 44 and $42 \mathrm{KDa}$, respectively. JNK1 and 2 correspond to 46 and $54 \mathrm{KDa}$, respectively.

$(p<0.001)$. Finally, no significant differences in proliferation rate between epithelium and mesenchyme were observed.

IL-6 neutralizing studies. In Figure 6, results of morphometric analysis (Fig. 6A, left panels) and proliferation studies (Fig. $6 B$, right panels) in normal lung explants treated with normal goat IgG (control) and IgG anti-rat IL-6 antibodies are shown. IL-6 blocking antibodies significantly reduced the number of peripheral airway buds, epithelial perimeter and epithelial and mesenchymal cellular proliferation rate.

MAPK signaling pathway. Normal lung explants treated with IL-6 at $10 \mathrm{pg} / \mathrm{mL}$ (dose with maximal effect), presented (semi-quantitative analysis) an enhanced p-38 kinase phosphorylation when compared with nontreated explants. No differences were observed in MEK1/2 and SAPK/JNK phosphorylation (Fig. 7).

\section{DISCUSSION}

This study demonstrated that IL-6 was constitutively expressed in pulmonary primitive epithelium, during all studied gestational ages of lung development, presenting highest levels of expression during pseudoglandular stage. Blocking IL-6 significantly reduced branching and cellular proliferation rate in normal explants, whereas IL-6 supplementation, either in normal or hypoplastic fetal lung explants, induced a biphasic effect on branching and cellular proliferation rate, with increased effect at lower doses, while no additional effect was obtained with the highest dose. These effects of IL-6 are most likely mediated through MAPK signaling pathway via p38.

IL-6 is a multifunctional inflammatory cytokine with important roles in cell proliferation, differentiation, growth, and apoptosis (2-4). Several clinical and experimental studies have investigated IL-6 role in pathophysiology of different lung diseases. In the adult, IL-6 has a critical role on inflammatory pathogenesis of acute respiratory distress syndrome
(23), asthma (24), chronic obstructive pulmonary disease (25), and non-small-cell lung cancer (26). IL-6 role during prenatal and neonatal period has been studied since decreased risk of respiratory distress syndrome in preterm neonates was demonstrated $(10,11)$. In fact, it has been proved that inflammatory mediators, namely IL-6, promote fetal lung maturation by inducing SP-A expression and protein synthesis consequently improving lung mechanics and gas exchange $(10,11)$. Studies carried on different animal models of intra-amniotic inflammation corroborated these observations in neonates exposed to chorioamnionitis $(12-15,27,28)$.

Pulmonary development is a complex process involving two different cellular phenomena, growth and maturation (1). All previous studies concerning the effect of IL-6 on prenatal lung development had focused mainly in maturation processes in a pathologic inflammatory context $(11-15,27,28)$. In this study, however, it was demonstrated that IL-6 was constitutively expressed in normal primitive lung epithelium throughout the studied ages. Interestingly, the epithelial IL-6 expression is in agreement with the findings previously documented in adult lung (29). In adults, epithelial expression was also observed in other branching organs such as salivary glands (30), prostate $(8,9)$, and mammary gland (7). However, IL-6 expression in fetuses was only described during submandibular gland morphogenesis $(5,6)$. In fact, Melnick et al. (5) showed a significant increase in IL-6 mRNA with progressive salivary gland development. Conversely, the current study demonstrated that in fetal lung the highest IL-6 mRNA levels occurred during early pseudoglandular stage decreasing progressively in subsequent stages of lung development.

Hypothesizing that IL-6 has a role during lung branching morphogenesis, normal fetal lung explants were cultured with increasing doses of IL-6 or with IL-6 neutralizing antibodies. Furthermore, IL-6 effect in nitrofen-induced hypoplastic lungs was also studied since it is well established that these lungs have restricted branching $(31,32)$. This work clearly demonstrated that IL-6 supplementation induced a biphasic pattern on branching either in normal or hypoplastic explants. In fact, lower doses of IL-6 induced an increase in growth rate (total number of peripheral airways buds and epithelial perimeter) of normal and hypoplastic lung explants, whereas highest dose did not accomplish additional effect. These observations were corroborated by proliferation studies, which demonstrated that $10 \mathrm{pg} / \mathrm{mL}$ of IL-6 (maximal effect on branching) significantly increased Ki-67 epithelial and mesenchymal positive cells. On the other hand, $100 \mathrm{pg} / \mathrm{mL}$ of IL-6 induced no significant changes in proliferation rate when compared with nontreated explants. Interestingly, it seems that IL-6's effects were exacerbated in nitrofen explants. Although nitrofen explants are smaller at $\mathrm{D}_{0}$, after $4 \mathrm{~d}$ in culture, no significant differences between normal and nitrofen explants could be detected (Table 2). The ability of hypoplastic explants to grow in culture with higher rates than normal explants had already been previously observed (33), however, the explanation for this phenomenon remains to be elucidated. A possible explanation consists in hypoplastic lungs eliciting up-regulation of some effectors as documented for neuroendocrine cellular products (33). Interestingly, it was also reported that end-gestation 
human hypoplastic lungs present higher production of tumor necrosis factor- $\alpha$ than normal lungs (34).

Regarding the biphasic pattern of IL-6 effects on branching rate, it is interesting to stress that previous studies relating inflammation, lung maturation, and incidence of respiratory distress syndrome (RDS) report a similar pattern. In fact, although intrauterine infection seems to protect very premature infants against RDS, high quantities of pro-inflammatory cytokines cause serious disease (35). On the other hand, our findings suggest that IL-6 is constitutively produced during the earliest gestational stages, which may contribute for the explanation of enhanced fetal lung tolerance to inflammation during early gestation when compared with later gestation (26).

Although IL-6 knockout mice do not seem to have significant lung development abnormalities (36-38), this study clearly suggests a physiologic role of IL-6 in lung branching morphogenesis. Although previous studies on IL-6 and lung development emphasized maturational process, the highest expression of IL-6 on the early fetal lung development stages suggests that the physiologic role for IL-6 is most likely linked to branching.

Previous reports demonstrated epithelial expression of functional IL-6 receptor during fetal lung development $(4,39)$. The mechanism responsible for IL-6 enhancing effects during lung branching morphogenesis is most likely dependent on gp130 signaling pathway through Stat3 and/or MAPK (2-4). In fact, it seems that IL-6 signaling through Stat 3 is important to normal submandibular gland morphogenesis in the mouse (5) as well as in human prostate cancer cell growth (40). Additionally, adult rat mammary gland remodeling depends on gp130 signaling through Stat3 and MAPK (7). None of the previous studies implied JAK/STAT signaling pathway in fetal lung growth mechanisms. In contrast, MAPK signaling was recently suggested as a crucial pathway for fetal lung development (18). Thus, MAPK pathway activation by IL-6 in fetal lung development was investigated. Explants treated with $10 \mathrm{pg} / \mathrm{mL}$ IL-6 were selected due to its maximal effect on growth. These experiments clearly show activation of p38MAPK by IL- 6 treatment, whereas no significant activation of MEK1/2 and JNK pathways was observed.

In conclusion, IL-6 epithelial expression throughout fetal lung development as well as the present in vitro studies suggest a physiologic role for endogenous IL-6 on pulmonary branching mechanisms most likely involving p38-MAPK intracellular pathway.

Acknowledgments. The authors thank Dr. Georg H. Fey for providing the plasmid with IL-6 for the riboprobe synthesis.

\section{REFERENCES}

1. Warburton D, Bellusci S, De Langhe S, Del Moral PM, Fleury V, Mailleux A, Tefft D, Unbekandt M, Wang K, Shi W 2005 Molecular mechanisms of early lung specification and branching morphogenesis. Pediatr Res 57:26R-37R

2. Heinrich PC, Behrmann I, Hann S, Hermanns HM, Muller-Newen G, Schaper F 2003 Principles of interleukin (IL)-6-type cytokine signaling and its regulation. Biochem J 374:1-20

3. Xing Z, Gauldie J, Cox G, Baumann H, Jordana M, Lei XF, Achong MK 1998 IL-6 is an anti-inflammatory cytokine required for controlling local or systemic acute inflammatory responses. J Clin Invest 101:311-320
4. Dame JB, Juul SE 2000 The distribution of receptors for the pro-inflammatory cytokines interleukin (IL)-6 and IL-8 in the developing human fetus. Early Hum Dev 58:25-39

5. Melnick M, Chen H, Zhou YM, Jaskoll T 2001 Interleukin-6 signaling and embryonic mouse submandibular salivary gland morphogenesis. Cells Tissues Organs 168:233-245

6. Jaskoll T, Melnick M 1999 Submandibular gland morphogenesis: stage-specific expression of TGF- $\alpha / \mathrm{EGF}$, IGF, TGF- $\beta$, TNF, and IL-6 signal transduction in normal embryonic mice and the phenotypic effects of TGF- $\beta 2$, TGF- $\beta 3$, and EGF-R null mutations. Anat Rec 256:252-268

7. Zhao L, Hart S, Cheng J, Melenhorst JJ, Bierie B, Ernst M, Stewart C, Schaper F, Heinrich PC, Ullrich A, Robinson GW, Hennighausen L 2004 Mammary gland remodeling depends on gp130 signaling through STAT3 and MAPK. J Biol Chem 279:44093-44100

8. Tatoud R, Desgrandchamps F, DeGeorges A, Thomas F 1993 Peptide growth factors in the prostate. Pathol Biol 41:731-740

9. Culig Z, Steiner H, Bartsch G, Hobisch A 2005 Interleukin-6 regulation of prostate cancer cell growth. J Cell Biochem 95:497-505

10. Jobe AH, Ikegami M 2001 Antenatal infection/inflammation and postnatal lung maturation and injury. Respir Res 2:27-32

11. Shimoya K, Taniguchi T, Matsuzaki N, Moriyama A, Murata Y, Kitajima H, Fujimura M, Nakayama M 2000 Chorioamnionitis decreased incidence of respiratory distress syndrome by elevating fetal interleukin-6 serum concentration. Hum Reprod 15:2234-2240

12. Ikegami T, Tsuda A, Karube A, Kodama H, Hirano H, Tanaka T 2000 Effects of intrauterine IL- 6 and IL- 8 on the expression of surfactant apoprotein mRNAs in the fetal rat lung. Eur J Obstet Gynecol Reprod Biol 93:97-103

13. Willet KE, Jobe AH, Ikegami M, Newnham J, Brennan S, Sly PD 2000 Antenatal endotoxin and glucocorticoid effects on lung morphometry in preterm lambs. Pediatr Res 48:782-788

14. Willet KE, Kramer BW, Kallapur SG, Ikegami M, Newnham JP, Moss TJ, Sly PD, Jobe AH 2002 Intra-amniotic injection of IL-1 induces inflammation and maturation in fetal sheep lung. Am J Physiol Lung Cell Mol Physiol 282:L411-L420

15. Bachurski CJ, Ross GF, Ikegami M, Kramer BW, Jobe AH 2001 Intra-amniotic endotoxin increases pulmonary surfactant proteins and induces SP-B processing in fetal sheep. Am J Physiol Lung Cell Mol Physiol 280:L279-L285

16. McClintock JY, Wagner EM 2005 Role of IL-6 in systemic angiogenesis of the lung. J Appl Physiol 99:861-866

17. Parera MC, van Dooren M, van Kempen M, de Krijgner R, Grosveld F, Tibboel D, Rottier R 2005 Distal angiogenesis: a new concept for lung vascular morphogenesis. Am J Physiol Lung Cell Mol Physiol 288:L141-L149

18. Kling DE, Lorenzo HK, Trbovich AM, Kinane TB, Donahoe PK, Schnitzer JJ 2002 Pre- and postnatal lung development, maturation, and plasticity: MEK-1/2 inhibition reduces branching morphogenesis and causes mesenchymal cell apoptosis in fetal rat lungs. Am J Physiol Lung Cell Mol Physiol 282:L370-L378

19. Tenbrinck R, Tibboel D, Gaillard JL, Kluth D, Bos AP, Lachmann B, Molenaar JC 1990 Experimentally induced congenital diaphragmatic hernia in rats. J Pediatr Surg 25:426-429

20. Henrique D, Adam J, Myat A, Chitnis A, Lewis J, Ish-Horowicz D 1995 Expression of a delta homologue in prospective neurons in the chick. Nature 375:787-790

21. Strahle U, Blader P, Adam J, Ingham PW 1994 A simple and efficient procedure for non-isotopic in situ hybridization to sectioned material. Trends Genet 10:75-76

22. Santos M, Bastos P, Gonzaga S, Roriz JM, Baptista MJ, Nogueira-Silva C, MeloRocha G, Henriques-Coelho T, Roncon-Albuquerque R Jr, Leite-Moreira AF, De Krijger, RR Tibboel D, Rottier R, Correia-Pinto J 2006 Ghrelin expression in human and rat fetal lungs and the effect of ghrelin administration in nitrofen-induced congenital diaphragmatic hernia. Pediatr Res 59:531-537

23. Bhatia M, Moochhala S 2004 Role of inflammatory mediators in the pathophysiology of acute respiratory distress syndrome. J Pathol 202:145-156

24. Doganci A, Sauer K, Karwot R, Finotto S 2005 Pathological role of IL-6 in the experimental allergic bronchial asthma in mice. Clin Rev Allergy Immunol 28:257-270

25. Chung KF 2001 Cytokines in chronic obstructive pulmonary disease. Eur Respir J Suppl 34:50s-59s

26. Bihl M, Tamm M, Nauck M, Wieland H, Perruchoud AP, Roth M 1998 Proliferation of human non-small-cell-lung-cancer cell lines: role of interleukin-6. Am J Respir Cell Mol Biol 19:606-612

27. Moss TJ, Newnham JP, Willett KE, Kramer BW, Jobe AH, Ikegami M 2002 Early gestational intra-amniotic endotoxin: lung function, surfactant, and morphometry. Am J Respir Crit Care Med 165:805-811

28. Kramer BW, Kramer S, Ikegami M, Jobe AH 2002 Injury, inflammation, and remodeling in fetal sheep lung after intra-amniotic endotoxin. Am J Physiol Lung Cell Mol Physiol 283:L452-L459

29. Takizawa H, Ohtoshi T, Ohta K, Hirohata S, Yamaguchi M, Suzuki N, Ueda T, Ishii A, Shindoh G, Oka T, Hiramatsu K, Ito K 1992 Interleukin 6/B cell stimulatory factor-II is expressed and released by normal and transformed human bronchial epithelial cells. Biochem Biophys Res Commun 187:596-602

30. Brennan MT, Fox PC 2000 Cytokine mRNA expression in the labial salivary glands of healthy volunteers. Oral Dis 6:222-226

31. Chinoy MR 2002 Pulmonary hypoplasia and congenital diaphragmatic hernia: advances in the pathogenetics and regulation of lung development. J Surg Res 106:209-223

32. Correia-Pinto J, Baptista MJ, Pedrosa C, Estevao-Costa J, Flake AW, Leite-Moreira AF 2003 Fetal heart development in the nitrofen-induced $\mathrm{CDH}$ rat model: the role of mechanical and nonmechanical factors. J Pediatr Surg 38:1444-1451 
33. Keijzer R, Liu J, Deimling J, Tibboel D, Post M 2000 Dual-hit hypothesis explains pulmonary hypoplasia in the nitrofen model of congenital diaphragmatic hernia. Am J Pathol 156:1299-1306

34. Ohshiro K, Miyazaki E, Taira Y, Puri P 1998 Upregulated tumor necrosis factoralpha gene expression in the hypoplastic lung in patients with congenital diaphragmatic hernia. Pediatr Surg Int 14:21-24

35. Hallman M, Glumoff V, Ramet M 2001 Surfactant in respiratory distress syndrome and lung injury. Comp Biochem Physiol A Mol Integr Physiol 129:287-294

36. Bluethmann H, Rothe J, Schultze N, Tkachuk M, Koebel P 1994 Establishment of the role of IL-6 and TNF receptor 1 using gene knockout mice. J Leukoc Biol 56:565-570
37. Poli V, Balena R, Fattori E, Markatos A, Yamamoto M, Tanaka H, Ciliberto G, Rodan GA, Costantini F 1994 Interleukin-6 deficient mice are protected from bone loss caused by estrogen depletion. EMBO J 13:1189-1196

38. Sugawara I, Mizuno S, Yamada H, Matsumoto M, Akira S 2001 Disruption of nuclear factor-interleukin-6, a transcription factor, results in severe mycobacterial infection. Am J Pathol 158:361-366

39. Takizawa H, Ohtoshi T, Yamashita N, Oka T, Ito K 1996 Interleukin 6-receptor expression on human bronchial epithelial cells: regulation by IL-1 and IL-6. Am J Physiol 270:L346-L352

40. Lou W, Ni Z, Dyer K, Tweardy DJ, Gao AC 2000 Interleukin-6 induces prostate cancer cell growth accompanied by activation of stat 3 signaling pathway. Prostate 42:239-242 